\title{
Water Relations of Vitis vinifera L. cv. Sunred Seedless in Response to Soil Water Depletion Before Harvest
}

\author{
P.A. Myburgh and C.L. Howell \\ ARC Infruitec-Nietvoorbij, Private Bag X5026, Stellenbosch 7599, South Africa
}

Submitted for publication: May 2006

Accepted for publication: June 2006

Key words: table grapes, irrigation, sap flux, stomatal control, water potential

\begin{abstract}
Effects of soil water depletion level and irrigation cut off during ripening on water stress in Sunred Seedless table grapes were studied in a field trial in the Hex River Valley of South Africa. Water status of grapevines subjected to four irrigation treatments was determined prior to harvest during the 2000/01 season. Grapevines of all treatments were irrigated at $40 \%$ plant available water (PAW) depletion before véraison. From véraison, i.e. the onset of ripening in December, until harvest at the end of January, two treatments were irrigated at $20 \%$ and $40 \%$ PAW depletion, respectively. Two more treatments were applied by cutting off irrigation at $20 \%$ PAW depletion when total soluble solids reached $12^{\circ} \mathrm{B}$ and $15^{\circ} \mathrm{B}$, respectively. Pre-dawn water stress in grapevines irrigated at $20 \% \mathrm{PAW}$ depletion until harvest was less than in those where irrigation was cut off at $12^{\circ} \mathrm{B}$. Sap flow measurements indicated that partial stomatal closure seemed to have occurred over the warmest part of the day. Apparently, stomatal control limited $\Psi_{1}$ differences between treatments although extensive soil water depletion occurred where irrigation was cut off during ripening. If accumulated leaf water potential $\left(\Psi_{T}\right)$ is considered, irrigation cut off at $12{ }^{\circ} B$ and $15^{\circ} \mathrm{B}$ induced more water stress in grapevines from 04:00 to 24:00 compared to those vines where irrigation was continued until harvest. Where irrigation was continued throughout the ripening period, the level of PAW depletion did not affect $\Psi_{\mathrm{T}}$. However, during the sunshine period (08:00 until 18:00), $\Psi_{\mathrm{T}}$ in grapevines subjected to 40\% PAW depletion, as well as those where irrigation was cut off, was higher than in the ones that were irrigated at $20 \%$ depletion until harvest. During the first half of the night, i.e. from 18:00 until 24:00, water potential in grapevines where irrigation was cut off at $12^{\circ} \mathrm{B}$ was unable to recover to the same level as in those exposed to the other treatments.
\end{abstract}

\section{INTRODUCTION}

Irrigation is necessary for the production of export quality table grapes in South Africa. It is well known that irrigation can affect table grape yield and quality (El-Ansary et al., 2005; Fourie, 1989; Myburgh, 1996; Van Rooyen et al., 1980). Vegetative growth, yield and quality are related to grapevine water status, as induced by different irrigation strategies (Fourie, 1989; Myburgh, 1996; Myburgh, 2003; Van Zyl, 1987). Hence, the optimum balance between vegetative growth, yield and quality should also be related to grapevine water status. Plant water status is commonly quantified by measuring leaf water potential $\left(\Psi_{1}\right)$ using the pressure chamber technique (Scholander et al., 1965). Generally, the onset of detrimental water stress in grapevines will occur if the pre-dawn or mid-day $\Psi_{1}$ falls below ca. $-0.5 \mathrm{MPa}$ and $-1.2 \mathrm{MPa}$, respectively (Williams et al., 1994). Due to soil variation, these $\Psi_{1}$ thresholds do not necessarily correspond to the same soil water contents or matric potentials in different soil types.

For micro-sprinkler irrigated Barlinka, an optimum balance between vegetative growth, yield and quality was obtained by irrigation at $40 \%$ plant available water (PAW) depletion. In these grapevines, $\Psi_{1}$ measured at 15:00 varied between -1.2 $\mathrm{MPa}$ and -1.3 MPa from December until February (Myburgh, 1996). Irrigation at $10 \%$ PAW depletion only reduced grape quality, whereas berry mass as well as grape quality was reduced at $60 \%$ PAW depletion. At the latter depletion level, $\Psi_{1}$ was persistently lower than -1.2 MPa over the same period compared to values that ranged between $-0.9 \mathrm{MPa}$ and $-1.2 \mathrm{MPa}$ where grapevines were irrigated at $10 \%$ PAW depletion. These findings showed that conditions for optimum grapevine response could be related to grapevine water status. Hence, measuring $\Psi_{1}$ would be a useful aid for scheduling the irrigation of table grape vineyards if similar relationships could be determined, and refined, for other cultivars.

The aim of this study was to determine the effects of the level of soil water depletion and irrigation cut off during ripening on plant water status in Sunred Seedless table grapes.

\section{MATERIALS AND METHODS}

The field trial was carried out on the experiment farm of ARC Infruitec-Nietvoorbij near De Doorns in the Hex River Valley (South Africa). Based on heat summation over the growing peri- 
od (September until March), this locality is a class IV climatic region (Saayman, 1981 and references therein) at $33^{\circ} 28^{\prime}$ South latitude. The soil, which belongs to the Fernwood form (Soil Classification Work Group, 1991), represented the sandy soils typical of the region. Sunred Seedless grapevines grafted onto Ramsey (Salt Creek) were used. Grapevines were planted $3.0 \mathrm{~m}$ x $1.8 \mathrm{~m}$ and trained onto a Trentina trellis (Avenant, 1990). The vineyard was irrigated with $32 \mathrm{~L} / \mathrm{h}$ micro-sprinklers with a $360^{\circ}$ distribution pattern, which wetted the total area. Soil water content was measured using a neutron probe which was calibrated for the specific soil. Level of PAW depletion was obtained from the relationship between soil water content and matric potential $\left(\Psi_{\mathrm{m}}\right)$ as described by Myburgh (2003).

The vineyard was six years old when the study was carried out during the 2000/01 season. Grapevines of all treatments were irrigated at $40 \%$ PAW depletion before véraison. From véraison, i.e. the onset of ripening in December, until harvest at the end of January, two treatments (T1 \& T4) were irrigated at $20 \%$ and $40 \%$ PAW depletion, respectively. Two more treatments (T2 \& T3) were applied by cutting off irrigation at 20\% PAW depletion level when total soluble solids reached $12^{\circ} \mathrm{B}$ and $15^{\circ} \mathrm{B}$, respectively. Treatments were replicated four times in a randomised block design. Each $324 \mathrm{~m}^{2}$ experiment plot contained eight experiment grapevines with two buffer grapevines at each end and two buffer rows on each side.

To quantify plant water status, diurnal leaf water potential was measured on 30 January 2001, shortly before the grapes were harvested. The pressure chamber technique was used to measure $\Psi_{1}$ (Scholander et al., 1965). Leaf water potential was measured every two hours from 04:00 until 24:00. An uncovered, mature leaf, fully exposed to sunlight (when applicable), was used on each experiment plot. Accumulated leaf water potential during the early morning (04:00 until 08:00), in full sunshine (08:00 until 18:00), during the first part of the night (18:00 until 24:00), as well as the total from 04:00 until 24:00, was calculated using the trapezoidal rule (Larson et al., 1994) as follows:

$\Psi_{\mathrm{T}}=\left[\left(0.5 \mathrm{x} \Psi_{0}\right)+\Psi_{1}+\Psi_{2}+\ldots . .+\Psi_{\mathrm{n}-1}+\left(0.5 \mathrm{x} \Psi_{\mathrm{n}}\right)\right] \mathrm{x} \Delta \mathrm{t} \quad$ (Eq. 1) where $\Psi_{\mathrm{T}}$ is accumulated leaf water potential $\left(\mathrm{MPa}^{2}\right), \Psi_{0}$ and $\Psi_{\mathrm{n}}$ are leaf water potential (MPa) measured at the beginning and end of the period, respectively, and $\Delta \mathrm{t}$ is the time interval ( $\mathrm{h}$ ) between measurements.

Xylem sap flux, i.e. flow per unit trunk cross-sectional area, was determined in grapevine trunks on two replications each of
T1, T2 and T3 on the same day as the $\Psi_{1}$ cycles, as well as on the next two days. Sap flux was measured at 15-minute intervals with the heat pulse velocity technique according to the protocol described by Myburgh (1998). On completion of these measurements, all leaves were removed from the grapevines in which sap flow was measured. Total leaf area of each grapevine was measured with an electronic area meter (Li3100, LI-COR, Nebraska). To convert sap flux to sap flow, trunk cross-sectional area was determined using the profile measuring apparatus described by Myburgh and Coetzee (2004). Transpiration was estimated by calculating the mean unit volume sap flow (L) per unit time (h) per unit leaf area $\left(\mathrm{m}^{2}\right)$. Atmospheric conditions were measured with an automatic weather station at the experiment farm.

The $\Psi_{1}$ data were subjected to an analysis of variance. Student's $t$ least significant difference (LSD) values were calculated to facilitate comparison between treatment means. Means which differed at $P \leq 0.05$ were considered to be significantly different. Due to limited equipment, sap flow replications were insufficient to allow reliable statistical analysis.

\section{RESULTS AND DISCUSSION}

When the diurnal $\Psi_{1}$ cycle for Sunred Seedless was determined prior to harvest, it had been 2 days, 18 days, 9 days and 6 days, respectively, since grapevines of the T1, T2, T3 and T4 treatments were irrigated. At that stage, PAW of the latter treatments had been depleted to $18 \%, 74 \%, 57 \%$ and $40 \%$, respectively. The corresponding $\Psi_{\mathrm{m}}$ amounted to ca. $-0.003 \mathrm{MPa},-0.008 \mathrm{MPa},-0.005 \mathrm{MPa}$ and -0.004 MPa, respectively. At 04:00 (pre-dawn), T2 grapevines experienced more water stress than $\mathrm{T} 1$ grapevines (see Fig. 1). However, pre-dawn $\Psi_{1}$ in $\mathrm{T} 1$ as well as $\mathrm{T} 2$ grapevines was still higher than $-0.5 \mathrm{MPa}$, which generally indicates severe water stress (Williams et al., 1994). From 06:00 (sunrise) until 10:00, irrigation cut off had no significant effect on water stress in grapevines. From 12:00 until 22:00, water stress in $\mathrm{T} 2$ grapevines was higher than in T1 ones, except at 14:00 and 16:00. Around 14:00, $\Psi_{1}$ in T1, T2 and T4 grapevines increased slightly, whereas water stress in T3 grapevines decreased to a minimum. The $\Psi_{1}$ increase in T1, T2 and $\mathrm{T} 4$ grapevines could not have been in response to abnormalities in diurnal patterns of net incoming solar radiation (insolation), air temperature, wind speed or vapour pressure deficit (VPD) on that particular day (see Fig. 2). Except for discrepancies over the warmest part of the day, differences in $\Psi_{1}$ between treatments appeared to be a function of $\Psi_{\mathrm{m}}$ (data not shown). Similar relationships were previously reported for other grape cultivars (Myburgh, 2003; Van Zyl, 1987; Williams, et al., 1994).

\section{TABLE 1}

Effect of plant available water (PAW) depletion and irrigation cut off during ripening on accumulated leaf water potential in Sunred Seedless during early morning (04:00 until 08:00), in full sunshine (08:00 until 18:00) and during the first part of the night (18:00 until 24:00), as measured prior to harvest on 30 January 2001 near De Doorns.

\begin{tabular}{|c|c|c|c|c|}
\hline \multirow[t]{2}{*}{ Treatment } & \multicolumn{4}{|c|}{ Accumulated leaf water potential $\left(\mathrm{MPa}^{2}\right)$} \\
\hline & 04:00 until 08:00 & 08:00 until 18:00 & 18:00 until 24:00 & Total \\
\hline T1 $-20 \%$ PAW depletion, irrigation continued & $0.71 \mathrm{a}^{(1)}$ & $7.93 \mathrm{a}$ & $1.43 \mathrm{a}$ & $10.01 \mathrm{a}$ \\
\hline $\mathrm{T} 2-20 \%$ PAW depletion, irrigation cut off at $12^{\circ} \mathrm{B}$ & $1.07 \mathrm{~b}$ & $9.53 \mathrm{c}$ & $2.95 \mathrm{~b}$ & $13.54 \mathrm{c}$ \\
\hline $\mathrm{T} 3-20 \%$ PAW depletion, irrigation cut off at $15^{\circ} \mathrm{B}$ & $0.92 \mathrm{ab}$ & $9.45 \mathrm{c}$ & $1.95 \mathrm{a}$ & $12.32 \mathrm{bc}$ \\
\hline T4 - 40\% PAW depletion, irrigation continued & $0.79 \mathrm{a}$ & $8.78 \mathrm{~b}$ & $1.60 \mathrm{a}$ & $11.16 \mathrm{ab}$ \\
\hline
\end{tabular}

(1) Any two means within a column not followed by the same letter are significantly different at $P \leq 0.05$. 


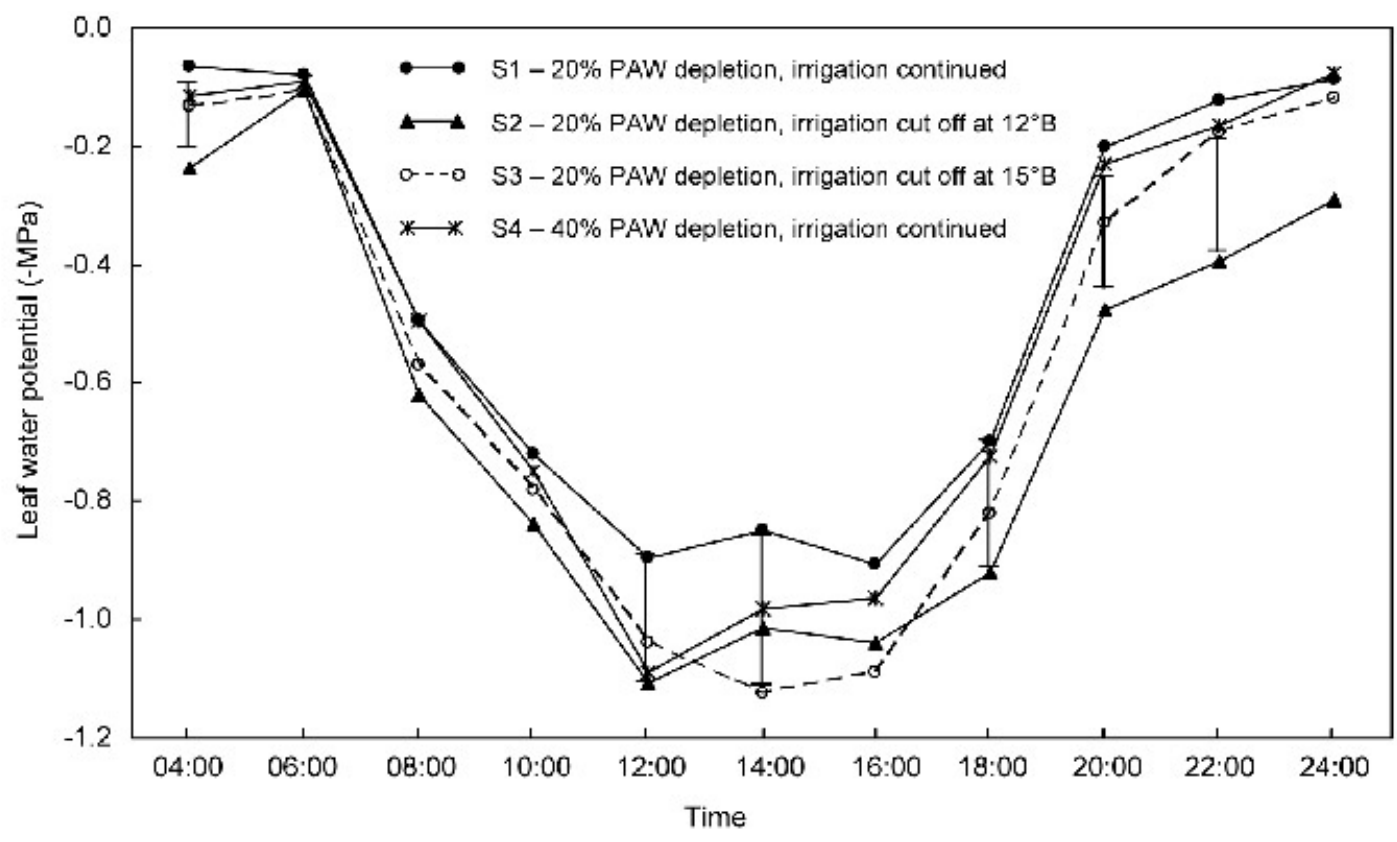

FIGURE 1

Effect of plant available water (PAW) depletion and irrigation cut off on leaf water potential in Sunred Seedless grapevines on sandy soil as measured prior to harvest on 30 January 2001 near De Doorns. Vertical bars indicate least significant difference $(P \leq 0.05)$.

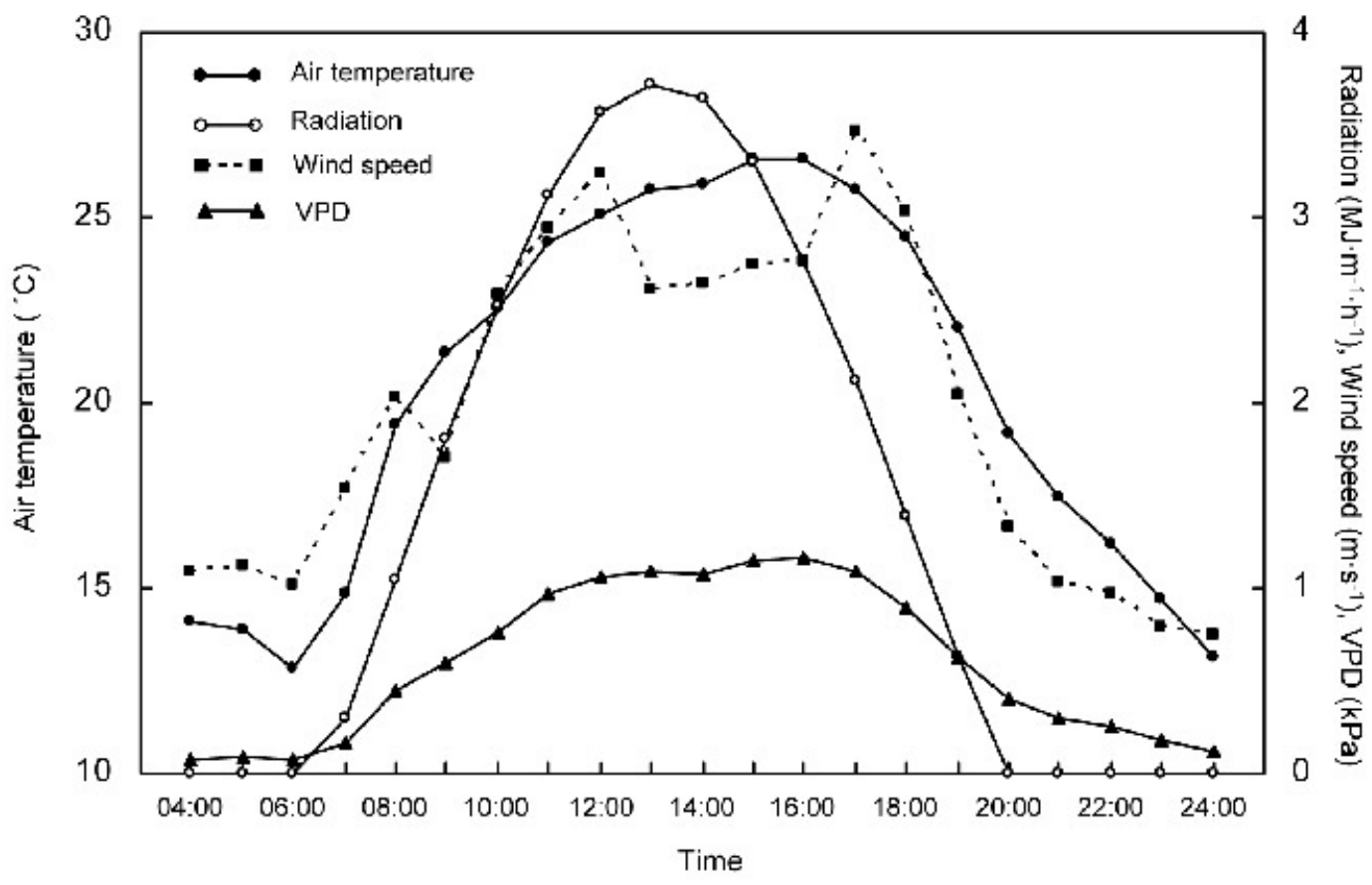

FIGURE 2

Air temperature, incoming solar radiation, wind speed and vapour pressure deficit (VPD) of the atmosphere as recorded on 30 January 2001 near De Doorns.

If accumulated leaf water potential is considered, irrigation cut off at $12^{\circ} \mathrm{B}$ and $15^{\circ} \mathrm{B}$ (T2 and T3) induced more water stress in grapevines from 04:00 to 24:00 than in those where irrigation was continued until harvest (T1) (see Table 1). Where irrigation was continued throughout the ripening period, the level of PAW depletion did not affect $\Psi_{\mathrm{T}}$. However, during the sunshine period (08:00 until 18:00), grapevines subjected to $40 \%$ PAW depletion, as well as those where irrigation was cut off, experienced more accumulated water stress than the ones that were irrigated at $20 \%$ depletion until harvest (see Table 1). During the first half of the night, i.e. from 18:00 until 24:00, water potential in T3 and T4 grapevines was able to recover to the same level as in $\mathrm{T} 1$ grapevines.

Water supply to $\mathrm{T} 1$ grapevines was sufficient to maintain fairly constant sap flux in full sunshine, except for a reduction around 


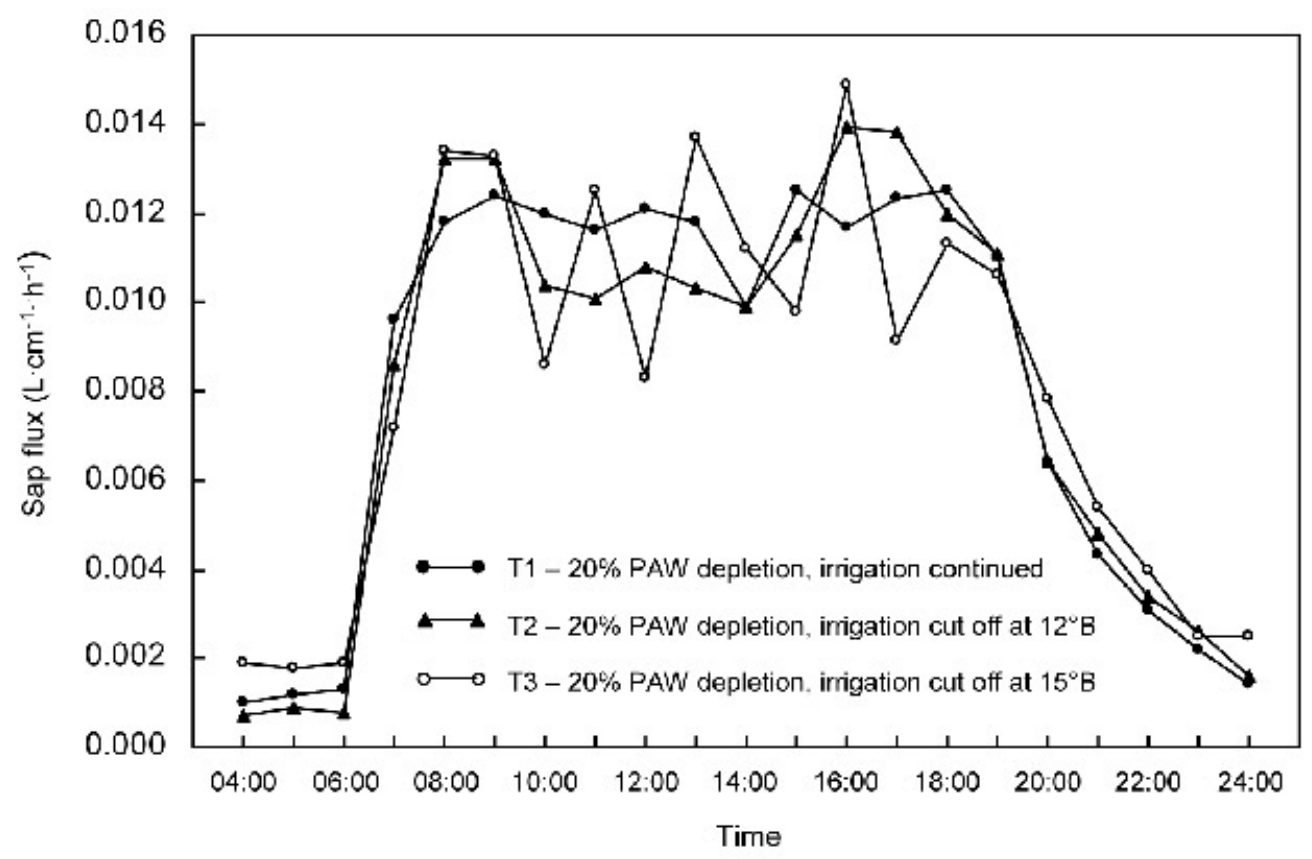

FIGURE 3

Effect of plant available water (PAW) depletion and irrigation cut off during ripening on xylem sap flux in Sunred Seedless grapevines determined on 30 January 2001 near De Doorns. Limited replication of sap flux measurements precluded statistical comparison.

14:00 (see Fig. 3). Since no sudden changes in net insolation, VPD or increased wind speed occurred that could have induced partial stomatal closure at that particular time of the day (see Fig. 2), water supply was probably restricted by some other mechanism. This mechanism probably prevented $\Psi_{I}$ from decreasing at 14:00 in comparison to the water stress levels maintained at 12:00 and 16:00 (see Fig. 1). In T2 grapevines, the reduced sap flux from 10:00 until 15:00 suggested that soil water deficits had limited water supply to the leaves earlier in the day, and for a considerably longer period compared to T1 grapevines (see Fig. 3). The net effect of the longer period of reduced sap flux was that $\Psi_{1}$ in T2 grapevines did not decrease at 14:00, although they were subjected to lower $\Psi_{\mathrm{m}}$ than $\mathrm{T} 1$ grapevines. The onset of reduced sap flux in $\mathrm{T} 3$ grapevines occurred after 09:00, but water uptake and flow to leaves was probably sufficient to increase the flux after approximately two hours (see Fig. 3). The reduced sap flux cycle was subsequently followed by two similar cycles, around 12:00 and 15:00. A fourth cycle occurred after 16:00, to reach the same minimum rate at 17:00 as the previous ones. However, the subsequent increase was constrained after 18:00, apparently by normal diurnal stomatal closure. These results suggested that transpiration of T3 grapevines exceeded water uptake, which resulted in water deficits at the root-soil interface. During the cycle of reduced water uptake, as indicated by the reduced sap flux, the water content of the surrounding soil was probably adequate to permit sufficient flow towards the root-soil interface, thereby reducing the water potential gradient. The lower gradient, in turn, allowed increased water uptake and sap flux rates. In the case of $\mathrm{T} 1$ grapevines, only one such cycle occurred around 14:00, whereas soil water content of the T2 treatments was insufficient to allow any significant increased water uptake during the warmest part of the day.

Variations in sap flow during the day were also observed in flood-irrigated Sultanina grapevines on alluvial soil in the Lower
Orange River region (Myburgh, 1998). Cyclic stomatal behaviour has been observed in many species, including cotton, pepper and sunflower (Barrs \& Klepper, 1968), citrus trees (Levy \& Kaufmann, 1976), rose bushes (Rose \& Rose, 1994) and grapevines (Düring, 2000; Düring \& Stoll, 1996). These oscillations can be the result of instability in either a $\mathrm{CO}_{2}$ control system or a water control system, or a combination thereof (Barrs, 1971). The period of oscillation can vary from less than one minute to more than an hour. Shallow, shorter oscillation periods are generally associated with control of $\mathrm{CO}_{2}$ status, whereas deeper, longer periods are associated with water status control (Barrs, 1971 and references therein). The generally accepted explanation is the following: as stomata open in the light, transpiration increases, leaf water content falls, and the associated water deficit causes partial stomatal closure, leaves regain turgor upon water inflow in response to the steepened water potential gradient, and finally $\Psi_{1}$ rises again, permitting stomata to re-open, thus re-commencing the cycle (Barrs \& Klepper, 1968). It was shown that stomatal oscillations in sunflower disappeared when $\Psi_{\mathrm{m}}$ fell below -0.1 MPa (Cox, 1968). The difference between air and leaf temperature (Cox, 1968), as well as $\mathrm{CO}_{2}$ exchange rate (Rose \& Rose, 1994), follow the cyclic stomatal behaviour. Increases in xylem potential (Levy \& Kaufmann, 1976) and $\Psi_{1}$ (Barrs \& Klepper, 1968) generally lag behind partial stomatal closure. The length of the lag period seems to increase due to increased root resistance at lower soil temperatures, i.e. longer at $5^{\circ} \mathrm{C}$ than at $25^{\circ} \mathrm{C}$ (Levy \& Kaufmann, 1976).

The mean trunk cross-sectional area was $0.0013 \mathrm{~m}^{2}, 0.0011 \mathrm{~m}^{2}$ and $0.0010 \mathrm{~m}^{2}$, respectively, for the T1, T2 and T3 grapevines in which sap flux was measured. The corresponding leaf areas of these grapevines were $9.4 \mathrm{~m}^{2}, 11.4 \mathrm{~m}^{2}$ and $11.5 \mathrm{~m}^{2}$, respectively. The combination of thicker trunk diameter and smaller leaf area contributed to the higher transpiration rates calculated for $\mathrm{T} 1$ grapevines 


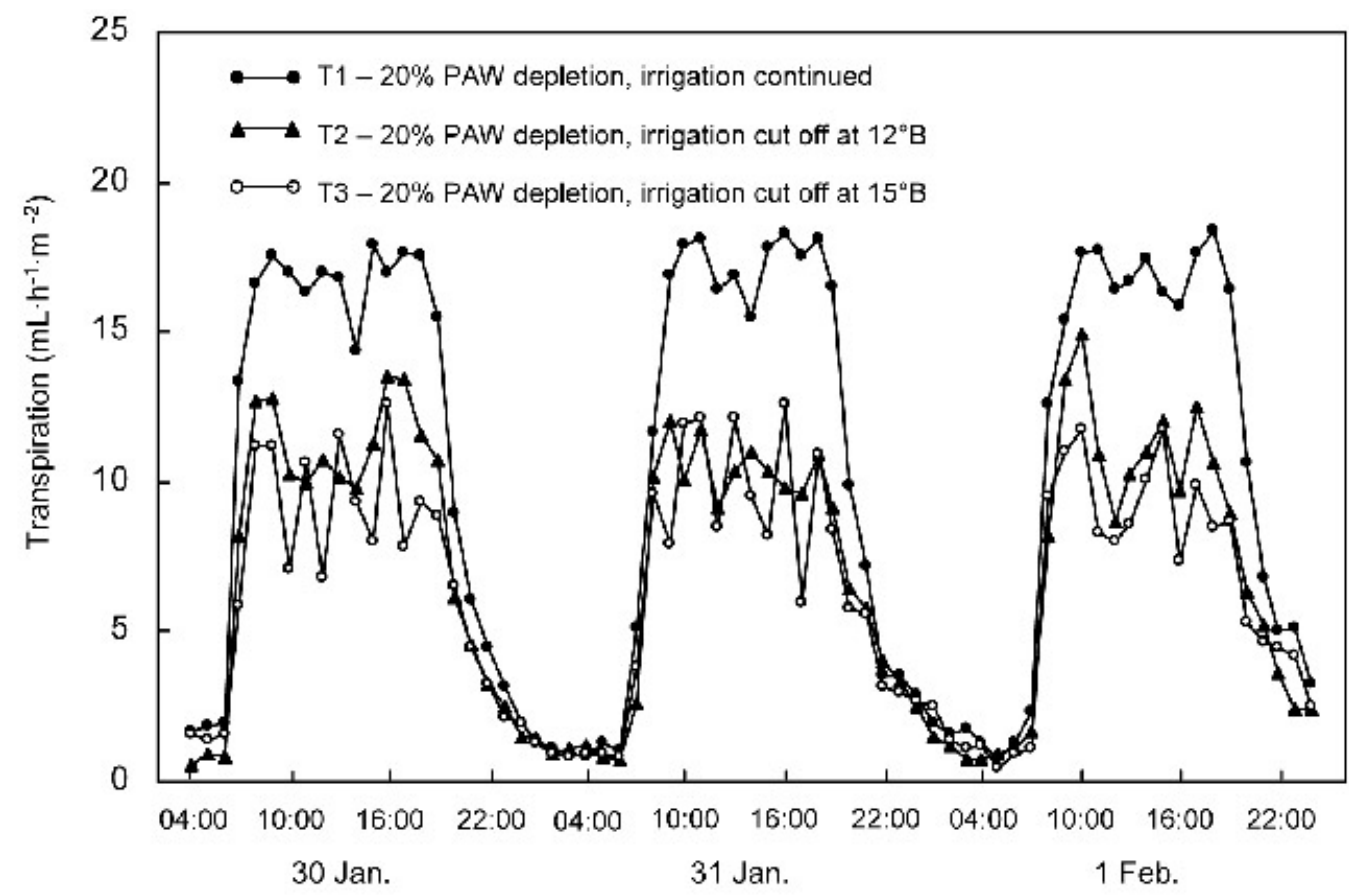

FIGURE 4

Effect of plant available water (PAW) depletion and irrigation cut off on calculated transpiration of Sunred Seedless grapevines as measured from 30 January to 1 February 2001 near De Doorns. Limited replication of sap flux measurements precluded statistical comparison.

compared to T2 and T3 ones (see Fig. 4). The cyclic behaviour of calculated transpiration continued to occur on 31 January and 1 February, although there were no drastic changes in the atmospheric conditions (data not shown). On 31 January, the calculated transpiration of T2 grapevines also showed some cyclic behavior, but to a lesser extent than T3 grapevines (see Fig. 4). On 1 February, only two cycles occurred around 12:00 and 16:00 in T1, T2 and T3 grapevines, respectively. However, the first cycle was more prominent in $\mathrm{T} 2$ and $\mathrm{T} 3$ grapevines than in the $\mathrm{T} 1$ ones. These results suggested that $\mathrm{T} 3$ grapevines were beginning to respond similarly to T2 ones as the soil dried out and hydraulic conductivity decreased.

\section{CONCLUSIONS}

Although the different $\Psi_{\mathrm{m}}$ values that were induced by the level of PAW depletion and irrigation cut off were relatively high, i.e. more than $-0.008 \mathrm{MPa}, \Psi_{1}$ in Sunred Seedless grapevines still responded to levels of soil water depletion. This suggested that soil hydraulic conductivity also played a role in determining the water status of grapevines in this particular medium-sand soil. Sap flux measurements showed that some sort of control seemed to have occurred during the warmest part of the day. In combination with the high $\Psi_{\mathrm{m}}$, apparent stomatal control not only prevented $\Psi_{1}$ decreasing below -1.2 $\mathrm{MPa}$, but also acted as a protective mechanism that avoided extremely high water stress in grapevines - particularly in the ones that were subjected to substantial soil water depletion where irrigation was cut off approximately three weeks before ripening. This indicated that $\Psi_{1}$ determined at a specific time of the day, particularly during the warmest part of the day, might not always be a reliable measure for differences in grapevine water status. Accumulated leaf water potential proved to be a more sensitive parameter to compare the effects of soil water depletion on grapevine water status. Hence, the cumulative effect of seemingly non-significant, but constant, $\Psi_{1}$ differences that occur over the course of the day between different levels of PAW depletion might eventually reflect in significant grapevine yield and quality differences.

\section{LITERATURE CITED}

Avenant, J.H., 1990. Trellising systems: single slanting, factory roof and trentina (Tyrolean). Farming in S. Afr. VORI 276/1990, ARC Infruitec-Nietvoorbij, Private Bag X5026, 7599 Stellenbosch, South Africa.

Barrs, H.D., 1971. Cyclic variations in stomatal aperture, transpiration, and leaf water potential under constant environmental conditions. Ann. Rev. Plant Physiol. 22, 223-236.

Barrs, H.D. \& Klepper, B., 1968. Cyclic variations in plant properties under constant environmental conditions. Physiol. Plant. 21, 711-730.

Cox, E.F., 1968. Cyclic changes in transpiration of sunflower leaves in a steady environment. J. Exp. Bot. 19, 167-175.

Düring, H., 2000. Induction of stomatal oscillations in grape leaves: Determination by gas exchange measurement. Vitis 39, 45-46.

Düring, H. \& Stoll, M., 1996. Stomatal patchiness in grapevine leaves. II. Uncoordinated stomatal movements. Vitis 35, 69-71.

El-Ansary, D.O., Nakayama, S., Hirano, K. \& Okamoto, G., 2005. Response of Muscat Alexandria table grapes to post-veraison regulated deficit irrigation in Japan. Vitis 44, 5-9.

Fourie, A., 1989. The effect of four soil water regimes on the performance of Barlinka table grapes in the Hex River Valley. Thesis, Stellenbosch University, Private bag X1, 7602 Matieland (Stellenbosch), South Africa.

Larson, R.E., Hostetler, R.P. \& Edwards, B.H., 1994. Calculus with analytic geometry. D.C. Heath and Company, Massachusetts.

Levy. Y. \& Kaufman, M.R., 1976. Cycling of leaf conductance in citrus exposed to natural and controlled environments. Can. J. Bot. 54, 2215-2218.

Myburgh, P.A., 1996. Response of Vitis vinifera L. cv. Barlinka/Ramsey to soil water depletion levels with particular reference to trunk growth parameters. S. Afr. J. Enol. Vitic. 17, 3-14. 
Myburgh, P.A., 1998. Water consumption of South African vineyards: A modelling approach based on the quantified combined effects of selected viticultural, soil and meteorological parameters. Thesis, Stellenbosch University, Private bag X1, 7602 Matieland (Stellenbosch), South Africa.

Myburgh, P.A., 2003. Responses of Vitis vinifera L. cv. Sultanina to level of soil water depletion under semi-arid conditions. S. Afr. J. Enol. Vitic. 24, 16-24.

Myburgh, P.A. \& Coetzee, F., 2004. Apparatus for non-destructive measurement of grapevine trunk cross-sectional area. S. Afr. J. Plant Soil 21, 67-69.

Rose, M.A., \& Rose, M.A., 1994. Oscillatory transpiration may complicate stomatal conductance and gas-exchange measurements. HortScience 29, 693-694.

Saayman, D., 1981. Klimaat, grond en wingerdbougebiede. In: J.D. Burger and J. Deist (eds.). Wingerdbou in Suid-Afrika. ARC Infruitec-Nietvoorbij, Private bag X5026, Stellenbosch 7599, South Africa.
Scholander, P.F., Hammel, H.T., Bradstreet, E.D. \& Hemmingsen, E.A., 1965. Sap flow in vascular plants. Science 148, 339-346.

Soil Classification Work Group, 1991. Soil classification - A taxonomic system for South Africa. Memoirs on natural resources of South Africa no. 15. Dept. Agric. Developm., Pretoria.

Van Rooyen, F.C., Weber, H.W. \& Levin, I., 1980. The response of grapes to a manipulation of the soil-plant-atmosphere continuum. I. Growth, yield and quality responses. Agrochemophysica 12, 59-68.

Van Zyl, J.L., 1987. Diurnal variation in grapevine water stress as a function of changing soil water status and meteorological conditions. S. Afr. J. Enol. Vitic. 8, 45-52.

Williams, L.E., Dokoozlian, N.K. \& Wample R., 1994. Grape, p. 85-133. In: Schaffer, B. and P.C. Anderson. (eds.). Handbook of environmental physiology of fruit crops, Vol I, Temperate crops. CRC Press, Boca Raton. 